\title{
Space Closure Rate in Mandibular Canine Retraction by Ni-Ti Closed Coil Spring: A Clinical Trial
}

\author{
Md. Kamrul Hasan ${ }^{* 1}$, Gazi Shamim Hassan², Samira Rahman ${ }^{3}$, Md. Sher Ali ${ }^{4}$, \\ Md. Azizur Rahman ${ }^{5}$, Md. Mahfuj Hasan ${ }^{6}$, Rokeya Rahman Tani ${ }^{7}$
}

\begin{abstract}
Introduction: In Majority of patients seeking orthodontic treatment, teeth must be extracted in order to obtain proper esthetics, occlusion, and stability as well as extraction of teeth is often a need to close residual space, after the initial decrowding and aligning. Pre adjusted fixed orthodontic appliances commonly utilize sliding mechanics for space closure with different types of force delivery systems. A variety of materials have been used as force delivery systems to close spaces between teeth as in the case of canine retraction after the extraction of premolars. Among all sliding or frictionless methods of canine retraction, super-elastic nickel titanium coil spring has a particular property in producing light continuous force at a long range of action, compared with previously available materials. Nickel-titanium closed coil spring, with a continuous action, might have some advantages in fixed appliance space closure mechanics. Materials and Methods: Over the period of one year from May 2015 to April 2016, this clinical trial was carried out and A total number of 20 patients (40 quadrants), who required canine retraction into first premolar extraction sites as part of their orthodontic treatment in the Department of Orthodontics of BSMMU selected as study population. The quadrants were affixed by nickel titanium closed coil springs (medium force, Ni-Ti extension spring, Ormco) with 200gm force measured by Correx Tension Gauge. Space closure was measured by means of direct measurement from the mesial surface of mesial wing of the 2nd premolar bracket and the distal surface of distal wing of the canine bracket with digital Vernier Calipers. Results: Mean space closer rate in mandibular canine retraction was $1.07 \pm 0.12 \mathrm{~mm} /$ month by nickel-titanium ( $\mathrm{Ni}$-Ti) closed coil spring method with $p$ value $<0.001$. Conclusion: This study revealed that space closer rate in mandibular canine retraction by nickel-titanium (Ni-Ti) closed coil spring is $1.07 \pm 0.12 \mathrm{~mm} / \mathrm{month}$.
\end{abstract}

Key words: Ni-Ti closed coil spring, Canine retraction.

Number of Figures: 04; Number of Table: 01; Number of References: 20; Number of Correspondence: 03.

*1. Corresponding Author: Dr. Md. Kamrul Hasan

Assistant Professor

Department of Orthodontics

Chattagram International Dental College, Chattagram.

E-mail : dr.kamrul_cmc@yahoo.com

Mobile: +88-01712513431

2. Prof. Dr. Gazi Shamim Hassan

Professor, Chairman \& Dean

Department of Orthodontics

Faculty of Dentistry, BSMMU, Dhaka.

3. Dr. Samira Rahman

Ex Medical Officer (Radiology and Imaging Dept.)

Chattagram Maa O Sishu Hospital, Chattagram.

4. Dr. Md. Sher Ali

Junior Consultant (Orthodontics)

Khulna Medical College, Khulna.

5. Dr. Md. Azizur Rahman

Orthodontist and Dental Surgeon

Ibn Sina Diagnostic and Consultation Center, Dhaka.

6. Dr. Md. Mahfuj Hasan

Lecturer

Department of Orthodontics

Shaheed Suhrawardy Medical College, Dhaka.

7. Dr. Rokeya Rahman Tani

FCPS Part- II Trainee

Dhaka Dental College, Dhaka.
Introduction:

Tweed's work revolutionized the field in the1940's and 1950's as it now became acceptable to extract teeth for orthodontic correction. In 1989, a survey of 238 orthodontists in Michigan was conducted to evaluate the prevalence of orthodontic extractions and found the mean rate of extraction treatment to be $39 \%$. The rate of extraction varied greatly between orthodontists ${ }^{1}$. On a daily basis, orthodontic patients present with malocclusions and or facial imbalance. Often times, teeth must be extracted in order to obtain proper esthetics, occlusion, and stability. Extraction of teeth can improve the facial esthetics of a patient with procumbent or protrusive lips. This can be accomplished by retracting the anterior teeth into the extraction spaces, thus retracting the lips to a more balanced position ${ }^{2,3,4}$. In severe crowding and extraction cases, the canines have been distalized to relive the crowding as space to correctly align the incisors will not be available. Canine retraction is a very important step in treatment of patients with crowding needed first premolar extraction. Orthodontic treatment involving extraction of teeth is often a need to close residual space, after the initial decrowding and aligning ${ }^{5,6,7}$. The closure of space can be achieved by two techniques, friction (sliding) mechanics or frictionless (loop) mechanics. Sliding (Frictional) mechanics involves either moving the brackets along the arch wire or sliding the arch wire through bracket \& tube. Loop (Frictionless) mechanics involves movement of teeth without the brackets sliding along the arch wire but with the help of loops ${ }^{8,9,10}$. 
Pre adjusted fixed orthodontic appliances commonly utilize sliding mechanics for space closure with different types of force delivery systems ${ }^{11,12}$. A variety of materials have been used as force delivery systems to close spaces between teeth as in the case of canine retraction after the extraction of premolars. These include latex elastics, coil spring, elastic module, elastomeric power chain, headgear and magnet ${ }^{13,14}$. Nickel-titanium (Ni-Ti) closed coil spring delivered constant force till the terminal end of deactivation stage is reached. The advantages of these springs are that they can be easily placed and removed without arch wire removal and do not need reactivation at each appointment; therefore, patient cooperation is not needed. The most time consuming stage of premolar extraction based orthodontic treatment is canine retraction. Any procedure which reduces the time required to retract canine will also serve to shorten overall treatment time. Reducing the duration of orthodontic treatment is of great interest to orthodontists $^{15,16,17}$. In context of Bangladesh, there is no study regarding space closure rate in canine retraction by any force system.

\section{Materials and Methods:}

Over the period of one year from May 2015 to April 2016, this clinical trial was carried out in the Department of Orthodontics at Bangabandhu Sheikh Mujib Medical University (BSMMU). A total number of 20 patients (40 quadrants), who required canine retraction into first premolar extraction sites as part of their orthodontic treatment selected as study population. Patients were selected on these criteria, Age between 15 to 30 years who needs to $1 \mathrm{st}$ premolar extraction for treatment, who gave consent for inclusion in the study and free from any systemic disease $^{18,19}$. All the patients were treated with pre adjusted edge-wise fixed appliance using stainless steel 0.018x0.025-inch slot Roth brackets. After all, first premolars were extracted, initial leveling and alignment was carried out. All teeth were ligated with $0.010^{\prime \prime}$ stainless steel litgature wire. Standardized anchorage control using tip back and toe in bend was used in all patients and 2nd premolars were included in anchorage unite. Then canine retraction carried out by individual sliding of canine using round 0.016-inch stainless steel arch wire with elastomeric Power Chain. The quadrants were affixed by nickel titanium closed coil springs (medium force, Ni-Ti extension spring, Ormco) with 200gm force measured by Correx Tension Gauge. In clinical practice, a four to six-week appointment interval is common ${ }^{20}$.

Space closure was measured by means of direct measurement from the mesial surface of mesial wing of the 2nd premolar bracket and the distal surface of distal wing of the canine bracket with digital Vernier Calipers every four weeks' interval.

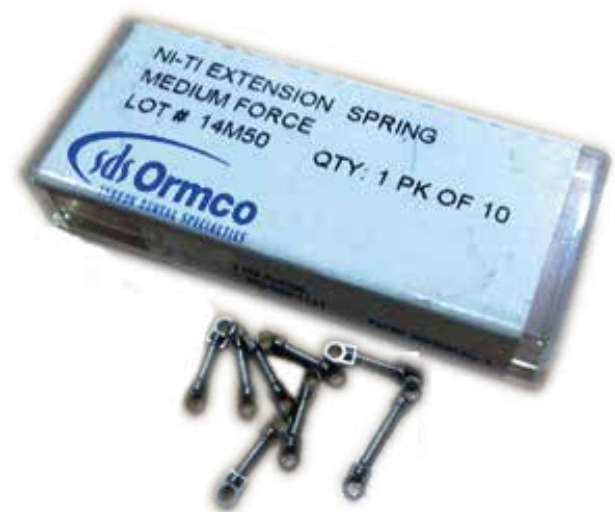

Figure-1: Ni-Ti Closed Coil Spring.

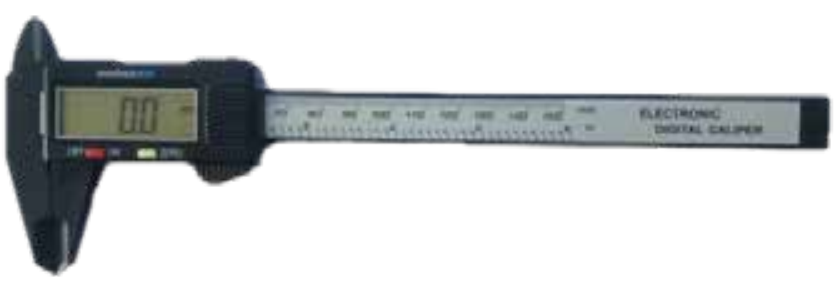

Figure-2: Digital Vernier Calipers.

Results:

During this study period distribution of patients according to gender, Female were predominant. Male female ratio was 1:4. Amongest the patients, Maximum 11 (55.0\%) were in age group 16-20 years followed by $7(35.0 \%)$ and 2 $(10.0 \%)$ were in age group 21-25 years and $>25$ years age group respectively. Mean of age was $20.60 \pm 3.54$ years within the range of 16-27 years.

Figure 3 shows distribution of patients according to gender. Female were predominant. Male female ratio was 1:4.

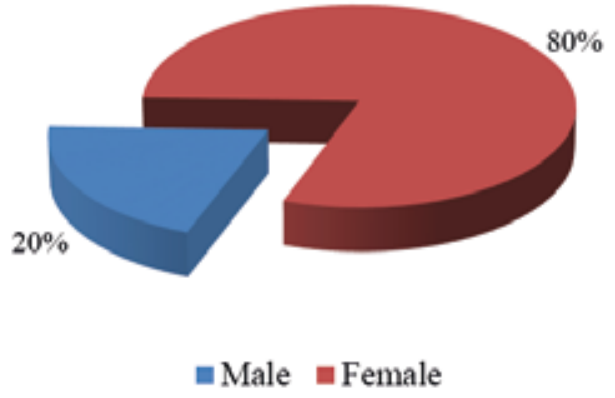

Figure-3: Pie chart of patients according to gender.

Table I shows distribution of patients according to age. Maximum $11(55.0 \%)$ were in age group 16-20 years followed by $7(35.0 \%)$ and $2(10.0 \%)$ were in age group $21-25$ years and $>25$ years age group respectively. Mean of age was $20.60 \pm 3.54$ years within the range of 16-27 years.

Table-I: Distribution of patients according to age.

\begin{tabular}{lll}
\hline Age & Frequency & Percentage \\
\hline $16-20$ & 11 & 55.0 \\
$21-25$ & 7 & 35.0 \\
$>25$ & 2 & 10.0 \\
\hline Total & $\mathbf{2 0}$ & $\mathbf{1 0 0 . 0}$ \\
\hline Mean \pm SD & $20.60 \pm 3.54$ & \\
\hline Range (Min - Max) & $16-27$ & \\
\hline
\end{tabular}


Figure 4 shows distribution of patients according to type of occlusion. Maximum $16(80.0 \%)$ cases were Bi-maxillary proclination and $4(20.0 \%)$ cases were Class 2 div 1 .

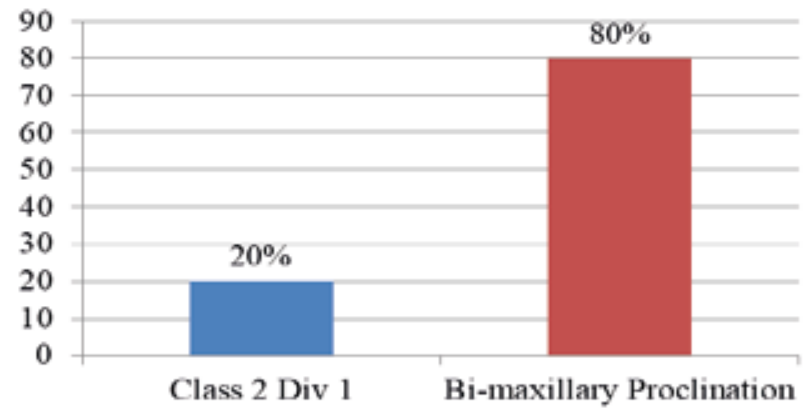

Figure-4: Bar diagram Distribution of patients according to type of occlusion.

\section{Discussion:}

A total of twenty patients were selected for canine retraction in the Department of Orthodontics at BSMMU. Among all patients female were predominant with male and female ratio 1:4. According to age distribution, mean age was measured $20.60 \pm 3.54$ years within the range of 16-27 years. Maximum patients were in age group 16-20 years which accounted $55.0 \%$ that followed by $35.0 \%$ and $10.0 \%$ were in age group 21-25 years and $>25$ years' age group respectively. Young populations especially female are more inclined to get a better aesthetic configuration of own self. This may be one of the causes of such type of age and sex distribution in our study. Among 17 patients in a study done by Samuels, Rudge, and Mair, there were 12 girls and 5 boys with a mean age of 14.7 years (range $=11.1$ to 17.1 years) ${ }^{14}$.

In this study, a majority of $80.0 \%$ cases were Bi-maxillary proclination and the rest of $20.0 \%$ cases were Class 2 div 1 . Mean space closer rate was $1.06 \pm 0.19 \mathrm{~mm} / \mathrm{month}$ in male and $1.07 \pm 0.10 \mathrm{~mm} /$ month in female in Ni-Ti closed coil spring method in mandible. There was no statistical significant difference between these two groups. Unpaired test was done to measure the level of significance.

In consideration of total time required for closing the space in canine retraction (months) was $6.25 \pm 0.91$ months in Ni-Ti closed coil spring method in mandible.

A clinical trial done in England on twenty seven patients and found $0.51 \mathrm{~mm} /$ week mean rate of tooth movement in nickel titanium closed coil springs group ${ }^{13,15}$.

In our study mean space closer rate in mandibular canine retraction is $1.07 \pm 0.12 \mathrm{~mm} / \mathrm{month}$ in $\mathrm{Ni}$-Ti closed coil spring method with $\mathrm{p}$ value $<0.001$.

\section{Conclusion:}

This study revealed that space closer rate by $\mathrm{Ni}$-Ti closed coil spring in mandibular canine retraction is $1.07 \pm 0.12$ $\mathrm{mm} / \mathrm{month}$.

\section{Conflict of Interest: None.}

\section{Acknowledgement:}

I would like to express my gratitude to all my teachers and supervisor who guide me and all my patients who in spite of their sorrows and sufferings helped me in getting all my clinical information. Last of all I like to acknowledge the sacrifice and support of my family members.

\section{References:}

01. Weintraub, J.A., Vig, P.S., Brown, C., et al. 'The prevalence of orthodontic extractions'. Am J Orthod Dentofacial Orthop. 1989: 96(6): 462-6.

https://doi.org/10.1016/0889-5406(89)90112-1

02. Proffit, W.R., Fields, H.W., Sarver, D.M. Contemporary Orthodontics.2012: 5th edn St. Louis, MO: Elsevier/Mosby. page-552.

03. Proffit, W.R. Contemporary orthodontics. Mosby, St Louis. 2nd edn: 1992.

04. Sowmya, K.S., Chandralekha, B., Uma, H.L., et al. Comparison of Active Tie Backs and Nickel Titanium Coil Springs in Canine Retraction: A Clinical Study with the MBT System. The Orthodontic Cyber Journal. 2011; Available from orthocj.com/2011/01/comparison-of-active-tiebacks-and-nickel-titanium-coil-springs-in-canine-retractiona-clinical-study-with-the-mbtsystem

05. Dixon, V., Read, M.J.F., O'Brien, K.D. 'Worthington $\mathrm{HV}$ and Mandall NA. A randomized clinical trial to compare three methods of orthodontic space closure'. J Orthod. 2002: 29(1): 31 - 36.

https://doi.org/10.1093/ortho/29.1.31

PMid:11907307

06. Graber, T.M., Vanarsdall, R.L., Vig, K.W.L. Orthodontics: Current Princples and Techniques. St. Louis, MO: Elsevier Mosby; 2005.

07. McLaughlin, R.P., Bennett, J.C., Travesi, H.J. Systematized orthodontic treatment mechanics. Edinburgh: Mosby; 2007.

08. Eliades, T., Gioka, C., Zineus, S, et al. 'Study of stress relaxation of orthodontic elastomers. pilot method report with continuous data collection in real time'. Hel Orthod Rev. 2003: 6: 13-26.

09. Kanuru, R.K., Azaneen, M., Narayana, V., et al. 'Comparison of canine retraction by in vivo method using four brands of elastomeric power chain'. J Int Soc Prevent Communit Dent. 2014: 4: S32-7.

https://doi.org/10.4103/2231-0762.144586

PMid:25452925 PMCid:PMC4247548

10. Chimenti, C., Lecce, D., Santucci, L., et al. 'In vitro assessment of elastomeric of elastomeric chain behavior'. Prog Orthod. 2001: 2(1): 42.

https://doi.org/10.1034/j.1600-9975.2001.20107.x 
11. Samuels, R.H., Rudge, S.J, and Mair, L.H.A. 'Comparison of the space closure using a nickel titanium spring and an elastic module: a clinical study'. Am J Ortho Dentofacial Orthop. 1993: 106(5):464 - 467.

https://doi.org/10.1016/S0889-5406(05)81798-6

12. Eberting, J.J., Straja, S.R., Tuncay, O.C. 'Treatment time, outcome, and patient satisfaction comparisons of Damon and conventional brackets'. Clin Orthod Res. 2001: 4: $228-234$.

https://doi.org/10.1034/j.1600-0544.2001.40407.x

PMid: 11683812

13. Sonis, A.L. 'Comparison of NiTi coil springs vs. elastics in canine retraction'. J Clin Orthod. 1994: 28(5): 293-5.

14. Samuels, R.H.A., Rudg, S.J., Mair, L.H. 'Study of space closure with nickel titanium closed coil spring and an elastic module'. Am J orthod. 1998: 114: 73-79.

https://doi.org/10.1016/S0889-5406(98)70241-0

15. Sonis, A.L., Van der Plas, E. and Gianelly, A. A comparison of elastomeric auxiliaries versus elastic thread on premolar extraction site closure: an in vivo study. American journal of orthodontics. 1986: 89(1): 73-78.

https://doi.org/10.1016/0002-9416(86)90115-6
16. Al-Sayagh, N.M., Ismael, A.J. 'Evaluation of space closure rate during canine retraction with nickel titanium closed coil spring and elastomeric chain'. Al-Rafidain Dent J. 2011: 11(1): 146-153.

https://doi.org/10.33899/rden.2011.9127

17. Kulshrestha, R.S., Tandon, R., Chandra, P. 'Canine retraction: A systematic review of different methods used'. Journal of Orthodontic Science. 2015: 4(1): 1-8.

https://doi.org/10.4103/2278-0203.149608

PMid:25657985 PMCid:PMC4314834

18. Miura, F., Mogi, M., Ohura, Y. et al. 'The super-elastic Japanese NiTi alloy wire for use in orthodontics part III. Studies on the Japanese NiTi alloy coil springs'. American Journal of Orthodontics and Dentofacial Orthopedics. 1988: 94(2): 89-96.

https://doi.org/10.1016/0889-5406(88)90356-3

19. Reitan, K. 'Clinical and histologic observations on tooth movement during and after orthodontic treatment'. Am J Orthod. 1967: 53(10):721-45.

https://doi.org/10.1016/0002-9416(67)90118-2

20. Jerrold, L., Naghavi, N. 'Evidence-based considerations for determining appointment intervals', J Clin Orthod, 2011: 45(7): 379--83. 